\title{
Incidence and risk factors of sexual dysfunction in young breast cancer survivors
}

\author{
Aiying Qi ${ }^{1}$, Yanping $\mathrm{Li}^{1}$, Huiying Sun ${ }^{1}$, Hui Jiao ${ }^{1}$, Yijin Liu ${ }^{2}$, Yuhui Chen ${ }^{1}$ \\ ${ }^{1}$ Department of General Surgery, the First Medical Center, Chinese PLA General Hospital, Beijing, China; ${ }^{2}$ Department of Radiology, the 8th \\ Medical Center of Chinese PLA General Hospital, Beijing, China \\ Contributions: (I) Conception and design: A Qi, Y Chen; (II) Administrative support: A Qi, Y Li; (III) Provision of study materials or patients: All \\ authors; (IV) Collection and assembly of data: H Sun, H Jiao; (V) Data analysis and interpretation: Y Liu; (VI) Manuscript writing: All authors; (VII) \\ Final approval of manuscript: All authors. \\ Correspondence to: Yuhui Chen. Attending Physician, Department of General Surgery, the First Medical Center of the Chinese PLA General \\ Hospital, 28 Fuxing Road, Haidian District, Beijing, China. Email: cyhnju@sina.com; Yijin Liu. Attending Physician, Postgraduate Student, \\ Department of Radiology, the 8th Medical Center of Chinese PLA General Hospital, No. 17, Heishanhu Road, Haidian District, Beijing, China. \\ Email: lyj1988819@163.com.
}

\begin{abstract}
Background Sexual dysfunction is common in postoperative breast cancer patients, which seriously affects the quality of life of the patients, especially young patients. The aim of the present study was to investigate the incidence and risk factors of sexual dysfunction in young breast cancer survivors, so as to provide evidence for further intervention.

Methods: A total of 201 young breast cancer patients who were hospitalized in our department from October 2017 to October 2018 were retrospectively enrolled. The general information questionnaire and the female sexual function index (FSFI) questionnaire were used to evaluate the patients.

Results: Of these patients, $83.08 \%$ (167/201) of young breast cancer patients had sexual dysfunction. Total mastectomy $(\mathrm{OR}$ value single factor $=7.843$, OR value multiple factor $=6.815)$, chemotherapy $(\mathrm{OR}$ value single factor $=11.876$, OR value multiple factor $=38.711)$, and endocrine therapy $(\mathrm{OR}$ value single factor $=19.688$, OR value multiple factor $=46.251)$ were independent risk factors of sexual dysfunction in young breast cancer survivors $(\mathrm{P}<0.05)$.

Conclusions: Our study suggests that the incidence of sexual dysfunction in young breast cancer survivors is at a high level. Increasing the rate of breast conserving surgery and targeted intervention in patients with risk factors may help to reduce the incidence of sexual dysfunction and improve the quality of life in young breast cancer survivors.
\end{abstract}

Keywords: Youth; breast cancer; sexual dysfunction; risk factors

Submitted Jan 21, 2021. Accepted for publication Apr 09, 2021.

doi: 10.21037/apm-21-352

View this article at: http://dx.doi.org/10.21037/apm-21-352

\section{Introduction}

Breast cancer has the highest incidence rate among all malignancies in women. According to statistics, breast cancer has become one of the main causes of death in female patients (1). Due to the developments in treatment, breast cancer patients can achieve a longer survival period after undergoing breast resection, lymph node dissection, radiotherapy, chemotherapy, endocrine therapy, and other measures. It was reported that the 5 -year survival rate after systemic treatment in breast cancer patients was as high as $76-92 \%$ (2). Most female breast cancer survivors not only need to prolong their survival time, but also need to improve their quality of life. Sexual dysfunction after breast cancer treatment is an important reason for the decline of patients' quality of life, and the incidence rate can be as high as $73.4 \%(3,4)$. Female sexual dysfunction (FSD) specifically refers to heterosexual women who are unable 
to produce the physiological response which is necessary for satisfactory sexual behavior (5). FSD includes sexual desire disorder, sexual arousal disorder, orgasm disorder and so on. With the improvements in the survival rates of breast cancer patients, sexual function rehabilitation is another rehabilitation goal. However, "sex" is a sensitive topic in both Eastern and Western cultures, and involves patients' personal privacy, only a few patients with FSD after breast cancer surgery communicate with medical staff. Therefore, the rehabilitation of patients with FSD is still an important issue. The purpose of this study was to investigate the incidence and risk factors of FSD in young breast cancer survivors, and to provide a theoretical basis for further intervention. And we found that total mastectomy, chemotherapy and endocrine therapy were independent risk factors of sexual dysfunction in young breast cancer survivors, which was different from a previous study (6).

We present the following article in accordance with the STROBE reporting checklist (available at http://dx.doi. org/10.21037/apm-21-352).

\section{Methods}

\section{General data}

A total of 201 patients with breast cancer who were hospitalized in our department from October 2017 to October 2018 were selected as the subjects. The inclusion criteria were as follows: (I) breast cancer (diagnosis based on pathological diagnosis); (II) having a spouse or fixed sexual partner, and the spouse or fixed sexual partner has no sexual dysfunction; (III) age $\leq 50$ years old at the time of enrollment; (IV) the patient had completed surgical treatment and postoperative adjuvant treatment (chemotherapy, radiotherapy, endocrine therapy, etc.); (V) patients were conscious and agreed to participate in the study. The exclusion criteria were as follows: (I) wounds had not healed after surgery; (II) stage IV breast cancer; (III) homosexuality; (IV) patients with sexual dysfunction before treatment; (V) living alone; (VI) patients with severe liver, kidney, or brain function damage, or other malignant tumors.

\section{Research methods}

\section{Research tools}

The general information questionnaire was used to investigate the general demographic data and diseaserelated information of the patients. General demographic data included the patient's age, body mass index (BMI), work intensity, education level, and annual income, amongst others. The clinical data included the type of operation, and whether or not the patient underwent chemotherapy, radiotherapy, and endocrine therapy. The female sexual function index (FSFI), which is one of the most commonly used scales to evaluate FSD worldwide $(7,8)$, is a self-rating scale used to evaluate the sexual function of heterosexual women over the past 4 weeks. The scale includes 6 modules: sexual desire, sexual arousal, vaginal wetness, orgasm, satisfaction, and pain, with a total of 19 items. The score of each item is between $0-5$ or $1-5$, and the score range of the scale is $2-36$. Generally speaking, an FSFI score $<26.55$ is considered as FSD. The lower the score, the more severe the symptoms of FSD. The ethical approval statement was not required due to the following reasons: (I) All procedures performed in this study involving human participants were in accordance with the Declaration of Helsinki (as revised in 2013). (II) Our study was a retrospectively observational study, and we only studied the clinical data of the patients, which will not bring any harm to the patients. (III) We will try our best to protect the information provided by patients from disclosing personal privacy. Individual consent for this retrospective analysis was waived.

\section{Survey method}

The general information questionnaire and the FSFI questionnaire were used to evaluate the patients (Repeat test was used to judge the results of the FSFI questionnaire). A total of 210 questionnaires were sent out. After excluding invalid questionnaires, 201 cases were enrolled in this study.

\section{Statistical analysis}

SPSS26.0 statistical software was used for data entry and analysis. A chi square test was used to analyze the count data of the 2 groups. The correlation between single factors and FSD was analyzed by fourfold data, and multiple factors were analyzed by logistic regression. $\mathrm{P}<0.05$ indicated that the difference was statistically significant. The FSFI score was expressed by $\mathrm{M}$ (P25, P75).

\section{Results}

The incidence of sexual dysfunction in young female breast cancer survivors

The mean FSFI score of the 201 female breast cancer 
survivors was $18.1(5.4,25.1)$. Of these patients, $16.92 \%$ did not have sexual dysfunction, and the mean FSFI score was 27.5 (26.7, 28.5). Furthermore, 83.08\% of the patients had FSD, and the mean FSFI score was 13.5 (4.8, 21.5). In the patients received total mastectomy, the incidence of FSD was $89.29 \%$.

\section{Risk factors of sexual dysfunction in young breast cancer survivors}

There were significant differences in age, type of operation, chemotherapy rate, and endocrine treatment rate between the 2 groups $(\mathrm{P}<0.05$; Table 1$)$. Total mastectomy was a risk factor for FSD in young breast cancer survivors ( $O R_{\text {single factor }}$ =7.843; Table 2). Chemotherapy was a risk factor for FSD in young breast cancer survivors $\left(\mathrm{OR}_{\text {single factor }}=11.876\right.$; Table 3). Endocrine therapy was a risk factor for FSD in young breast cancer survivors $\left(\mathrm{OR}_{\text {single factor }}=19.688\right.$; Table 4). Multivariate logistic regression analysis showed that total mastectomy, chemotherapy, and endocrine therapy were risk factors for FSD in young breast cancer survivors $\left(\mathrm{OR}_{\text {Multiple factor }}=6.815\right.$, 38.711, and 46.251, respectively, $\mathrm{P}<0.05$; Table 5).

\section{Discussion}

\section{Young female breast cancer survivors have a bigh incidence of FSD}

Sexual life is not only a fundamental aspect of normal life and intimate relationships between partners, but also an important factor in promoting the physical and mental recovery of patients $(8,9)$. However, some patients are influenced by traditional ideas, and they are more conservative about sexual problems. Patients with sexual problems seldom take the initiative to talk about sex (10). Sexual life problems of breast cancer patients not only exist during treatment, but can also occur after treatment. A recent study showed that the incidence of FSD in young women with breast cancer can be as high as $68 \%$ (11). Our study showed that the incidence of FSD in young breast cancer survivors was as high as $83.08 \%$. Other studies showed that $50-75 \%$ of breast cancer survivors had persistent sexual dysfunction $(12,13)$. In developed countries, the degree of openness regarding sexuality and people's satisfaction with sex are very high. The incidence of FSD in breast cancer is high, which seriously affects the physical, psychological, and social health status of patients after surgery, and even leads to the rupture of relationships between partners.

\section{Influencing factors of FSD in young breast cancer survivors}

At present, breast conserving surgery or mastectomy are the common surgical methods for breast cancer. It was reported that the impact of breast conserving surgery on sexual function is far less than that of total mastectomy $(14,15)$. Breasts are an important secondary sexual characteristic of women, and play an important role in body image, selfesteem, sexual pleasure, and sexual stimulation (16). The loss of breast and surgical scars can have a significant psychological impact on patients. Patients may believe that they have lost a fundamental part of being female. Therefore, they dare not expose their bodies in front of their lovers, and their self-confidence and self-esteem decline. As a result, tension, fear, doubt, and helplessness will appear, which can affect the sexual life of the spouse, leading to the occurrence of FSD.

Recent studies have confirmed that chemotherapy has a significant impact on female sexual function $(17,18)$. In particular, chemotherapy induces menopausal symptoms, such as decreased sexual desire, vaginal dryness, difficulty in sexual intercourse, and other adverse reactions, and eventually results in reduced frequency of sex and decreased intensity of orgasm (19). After chemotherapy, patients or family members can mistakenly believe that sexual activity will hinder the recovery of the disease and even lead to recurrence, and then deliberately restrain their own and their spouse's sexual desire, which seriously affects their relationship and their satisfaction with their sexual life. Fear of disease recurrence and the existence of negative emotions will lead to FSD in breast cancer patients (11).

Endocrine therapy is mainly used in patients with hormone receptor positive breast cancer. Whether it is used as an adjuvant therapy to prevent recurrence and metastasis after breast cancer surgery, or as a rescue treatment after recurrence and metastasis, endocrine therapy is very important (20). Endocrine therapy can reduce the levels of estrogen in the body or block the combination of estrogen and hormone receptors, thus blocking the promotion of estrogen-dependent breast cancer cell proliferation, so as to achieve the purpose of inhibiting tumor growth. However, it can also cause the appearance of menopausal symptoms, such as facial hot flashes, sleep disorders, and vaginal dryness and atrophy. 
Table 1 Comparison of clinical characteristics between young female breast cancer survivors with FSD or with no sexual dysfunction (n=201)

\begin{tabular}{|c|c|c|c|c|}
\hline Category & \multicolumn{2}{|c|}{ Sexual dysfunction } & $\chi^{2}$ value & $P$ value \\
\hline Age (year) & & & 7.971 & 0.019 \\
\hline $20-30$ & $2(1.20)$ & $3(8.82)$ & & \\
\hline $31-40$ & $33(19.76)$ & $9(26.47)$ & & \\
\hline $\mathrm{BMI}\left(\mathrm{kg} / \mathrm{m}^{2}\right)$ & & & 0.525 & 0.769 \\
\hline$\leq 23.9$ & $109(65.27)$ & $20(58.82)$ & & \\
\hline $24-27.9$ & $49(29.34)$ & $12(35.29)$ & & \\
\hline$\geq 28$ & 9 (5.39) & $2(5.88)$ & & \\
\hline High school/technical secondary school & $115(68.86)$ & $28(82.35)$ & & \\
\hline Junior high school and below & $38(22.75)$ & $2(5.88)$ & & \\
\hline Annual income & & & 3.290 & 0.193 \\
\hline$\leq 6$ ten thousand yuan & $91(54.49)$ & $13(38.24)$ & & \\
\hline $6-20$ ten thousand yuan & $74(44.31)$ & $20(58.82)$ & & \\
\hline$\geq 20$ ten thousand yuan & $2(1.20)$ & $1(2.94)$ & & \\
\hline Work intensity & & & 1.710 & 0.425 \\
\hline Light physical labor & $15(8.98)$ & $1(2.94)$ & & \\
\hline Chemotherapy & & & 43.122 & 0.000 \\
\hline Yes & $142(85.03)$ & $11(32.35)$ & & \\
\hline No & 25 (14.97) & $23(67.65)$ & & \\
\hline Radiotherapy & & & 1.813 & 0.178 \\
\hline Yes & $82(49.10)$ & $21(49.10)$ & & \\
\hline No & $85(50.90)$ & $13(61.67)$ & & \\
\hline Endocrine therapy & & & 53.869 & 0.000 \\
\hline Yes & 135 (80.84) & $6(17.65)$ & & \\
\hline No & $32(19.16)$ & $28(82.35)$ & & \\
\hline
\end{tabular}

BMI, body mass index; FSD, female sexual dysfunction. 
Table 2 Association between type of operation and FSD in young breast cancer survivors

\begin{tabular}{lccc}
\hline \multirow{2}{*}{ Type of operation } & \multicolumn{2}{c}{ Sexual dysfunction } & \\
\cline { 2 - 3 } & FSD group $(\mathrm{n}=167)$ & Non-FSD group $(\mathrm{n}=34)$ & 18 \\
\hline Total mastectomy & 150 & 16 & 33 \\
Breast conserving surgery & 17 & 34 & 201 \\
$\mathrm{n}$ & 167 & 34 \\
\hline
\end{tabular}

OR value of exposure ratio of the FSD group/exposure ratio of the non-FSD group $=7.843$. FSD, female sexual dysfunction.

Table 3 Association between chemotherapy and FSD in young breast cancer survivors

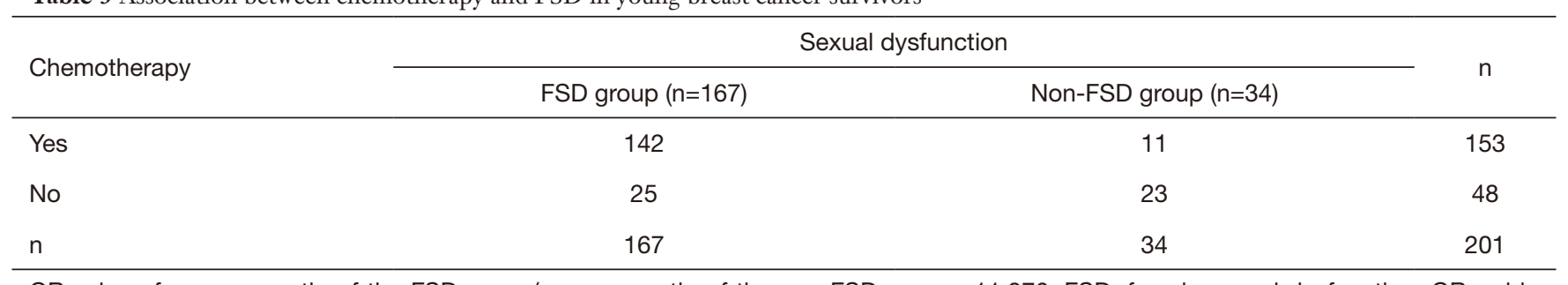

OR value of exposure ratio of the FSD group/exposure ratio of the non-FSD group $=11.876$. FSD, female sexual dysfunction; OR, odds ratio.

Table 4 Correlation between endocrine therapy and FSD in young breast cancer survivors

\begin{tabular}{lccc}
\hline \multirow{2}{*}{ Endocrine therapy } & Sexual dysfunction & & \\
\cline { 2 - 4 } & FSD group $(\mathrm{n}=167)$ & Non-FSD group $(\mathrm{n}=34)$ & \\
\hline Yes & 135 & 6 & 141 \\
No & 32 & 28 & 34 \\
$\mathrm{n}$ & 167 & 34 & 201 \\
\hline
\end{tabular}

OR value of exposure ratio of the FSD group/exposure ratio of the non-FSD group $=19.688$. FSD, female sexual dysfunction; OR, odds ratio.

Table 5 Multivariate logistic regression analysis of FSD in young breast cancer survivors

\begin{tabular}{lccccccc}
\hline Factor & B & Standard error & Wald & P value & OR value & \multicolumn{2}{c}{ EXP(B) 95\% Cl } \\
\cline { 5 - 7 } & & & & & & Lower bound & Upper bound \\
\hline 20-30 years old & 1.600 & 3.722 & 0.185 & 0.667 & 4.954 & 0.003 & 7297.422 \\
30-40 years old & 0.338 & 0.667 & 0.258 & 0.612 & 1.403 & 0.380 & 5.182 \\
Total mastectomy & 1.919 & 0.663 & 8.386 & 0.004 & 6.815 & 1.859 & 7.913 \\
Chemotherapy & 3.658 & 0.811 & 20.351 & 0.000 & 38.711 & 189.963 \\
Endocrine therapy & 3.834 & 0.810 & 22.397 & 0.000 & 46.251 & 9.452 & 226.324 \\
Constant value & -5.566 & 0.870 & 40.195 & 0.000 & & &
\end{tabular}

FSD, female sexual dysfunction; OR, odds ratio; Cl, confidence interval; EXP(B), the exponent of B. 


\section{Summary}

FSD is one of the most common problems in breast cancer patients after surgery, which affects the quality of sexual life, worsens intimate relationships, and greatly hinders the recovery of patients. According to the results of our study, the rate of breast conserving surgery should increase. For patients with high risk factors for FSD, early targeted intervention may help to reduce the incidence of FSD.

\section{Limitations}

This was a retrospectively study. We failed to study the long-term rehabilitation of patients with FSD.

\section{Acknowledgments}

Funding: None.

\section{Footnote}

Reporting Checklist: The authors have completed the STROBE reporting checklist. Available at http://dx.doi. org/10.21037/apm-21-352

Data Sharing Statement: Available at http://dx.doi. org/10.21037/apm-21-352

Conflicts of Interest: All authors have completed the ICMJE uniform disclosure form (available at http://dx.doi. org/10.21037/apm-21-352). The authors have no conflicts of interest to declare.

Ethical Statement: The authors are accountable for all aspects of the work in ensuring that questions related to the accuracy or integrity of any part of the work are appropriately investigated and resolved. The ethical approval statement was not required due to the following reasons: (I) All procedures performed in this study involving human participants were in accordance with the Declaration of Helsinki (as revised in 2013). (II) Our study was a retrospectively observational study, and we only studied the clinical data of the patients, which will not bring any harm to the patients. (III) We will try our best to protect the information provided by patients from disclosing personal privacy. Individual consent for this retrospective analysis was waived.
Open Access Statement: This is an Open Access article distributed in accordance with the Creative Commons Attribution-NonCommercial-NoDerivs 4.0 International License (CC BY-NC-ND 4.0), which permits the noncommercial replication and distribution of the article with the strict proviso that no changes or edits are made and the original work is properly cited (including links to both the formal publication through the relevant DOI and the license). See: https://creativecommons.org/licenses/by-nc-nd/4.0/.

\section{References}

1. Hu K, Ding P, Wu Y, et al. Global patterns and trends in the breast cancer incidence and mortality according to sociodemographic indices: an observational study based on the global burden of diseases. BMJ Open 2019;9:e028461.

2. Siegel RL, Miller KD, Jemal A. Cancer statistics, 2018. CA Cancer J Clin 2018;68:7-30.

3. Ferreira IS, Fernandes AFC, Rodrigues AB, et al. Accuracy of the Defining Characteristics of the Sexual Dysfunction Nursing Diagnosis in Women with Breast Cancer. Int J Nurs Knowl 2020;31:37-43.

4. Jing L, Zhang $\mathrm{C}, \mathrm{Li} \mathrm{W}$, et al. Incidence and severity of sexual dysfunction among women with breast cancer: a meta-analysis based on female sexual function index. Support Care Cancer 2019;27:1171-80.

5. K.T.K. Wong, M.K. Forbes Evidence that Relationship Quality, Social Support, and SSRI Use Do Not Account for the Shared Underlying Relationships among Symptoms of Depression, Anxiety, and Female Sexual Dysfunction. J Sex Res 2020;57:365-74.

6. Lee M, Kim YH, Jeon MJ. Risk factors for negative impacts on sexual activity and function in younger breast cancer survivors. Psychooncology 2015;24:1097-103.

7. Pérez-López FR, Ornat L, Lopez-Baena MT, et al. Association of female genital mutilation and female sexual dysfunction: A systematic review and meta-analysis. Eur J Obstet Gynecol Reprod Biol 2020;254:236-44.

8. Rosen R, Brown C, Heiman J, et al. The female sexual function index (FSFI): a multidimensional self-report instrument for the assessment of female sexual function. J Sex Marital Ther 2000;26:191-208.

9. da Costa FA, Ribeiro MC, Braga S, et al. Sexual Dysfunction in Breast Cancer Survivors: Cross-Cultural Adaptation of the Sexual Activity Questionnaire for Use in Portugal. Acta Med Port 2016;29:533-41.

10. Farthmann J, Hanjalicbeck A, Veit J, et al. The impact of chemotherapy for breast cancer on sexual function 
and health-related quality of life. Support Care Cancer 2016;24:2603-9.

11. Abril-Requena A, Garcia-Torres F, Alos FJ. Sexual dysfunction and phobic anxiety in breast cancer survivors. Psychooncology 2019;28:195-7.

12. Ljungman L, Ahlgren J, Petersson LM, et al. Sexual dysfunction and reproductive concerns in young women with breast cancer: Type, prevalence, and predictors of problems. Psychooncology 2018;27:2770-7.

13. Cornell LF, Mussallem DM, Gbison TC, et al. Trends in Sexual Function After Breast Cancer Surgery. Ann Surg Oncol 2017;24:2526-38.

14. Kedde H, van de Wiel HB, Weijmar Schultz WC, et al. Sexual dysfunction in young women with breast cancer. Support Care Cancer 2013;21:271-80.

15. Aerts L, Christiaens MR, Enzlin P, et al. Sexual functioning in women after mastectomy versus breast conserving therapy for early-stage breast cancer: a

Cite this article as: Qi A, Li Y, Sun H, Jiao H, Liu Y, Chen Y. Incidence and risk factors of sexual dysfunction in young breast cancer survivors. Ann Palliat Med 2021;10(4):4428-4434. doi: 10.21037/apm-21-352 prospective controlled study. Breast 2014;23:629-36.

16. Boquiren VM, Esplen MJ, Wong J, et al. Sexual functioning in breast cancer survivors experiencing body image disturbance. Psych oncology 2016;25:66-76.

17. Taylor CE, Meisel JL. Meisel Management of Breast Cancer Therapy-Related Sexual Dysfunction. Oncology (Williston Park) 2017;31:726-9.

18. Fréour T, Barrière P, Masson D. Anti-mullerian hormone levels and evolution in women of reproductive age with breast cancer treated with chemotherapy. Eur J Cancer 2017;74:1-8.

19. Moore HC. Impact on quality of life of adjuvant therapy for breast cancer. Curr Oncol Rep 2007;9:42-6.

20. Cavalheiro JA, Bittelbrunn A, Menke CH, et al. Sexual function and chemotherapy in postmenopausal women with breast cancer. BMC Womens Health 2012;12:28.

(English Language Editor: J. Jones) 